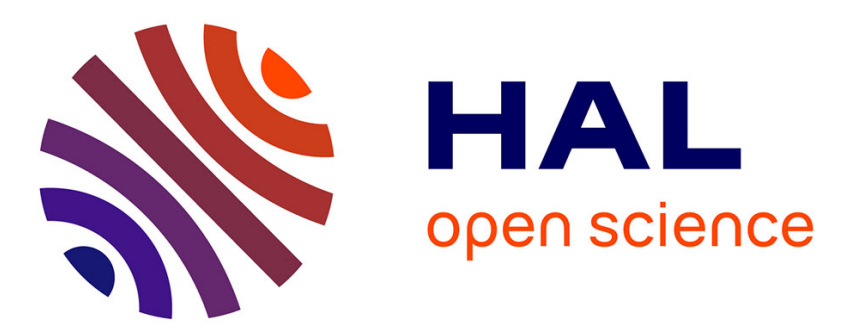

\title{
PERFORMANCE OF AN ENERGY COMPENSATOR WITH A LARGE ACCEPTANCE ANGLE
}

\author{
H. Andren
}

\section{To cite this version:}

H. Andren. PERFORMANCE OF AN ENERGY COMPENSATOR WITH A LARGE ACCEPTANCE ANGLE. Journal de Physique Colloques, 1986, 47 (C7), pp.C7-483-C7-488. 10.1051/jphyscol:1986781 . jpa-00225976

\section{HAL Id: jpa-00225976 https://hal.science/jpa-00225976}

Submitted on 1 Jan 1986

HAL is a multi-disciplinary open access archive for the deposit and dissemination of scientific research documents, whether they are published or not. The documents may come from teaching and research institutions in France or abroad, or from public or private research centers.
L'archive ouverte pluridisciplinaire HAL, est destinée au dépôt et à la diffusion de documents scientifiques de niveau recherche, publiés ou non, émanant des établissements d'enseignement et de recherche français ou étrangers, des laboratoires publics ou privés. 


\title{
PERFORMANCE OF AN ENERGY COMPENSATOR WITH A LARGE ACCEPTANCE ANGLE
}

\author{
H.O. ANDREN \\ Department of Physics, Chalmers University of Technology, \\ S-41296 Göteborg. Sweden
}

\begin{abstract}
Résumé - Un compensateur en énergie de type Poschenrieder pour une sonde à atomes est décrit. L'angle d'acceptance du compensateur est grand, 0.1 radians. La résolution en masse a été déterminée pour des angles d'entrance et des défaults d'énergie ionique différents, et est comparée à la tésolution en masse calculée des erreurs de focalisation du compensateur.
\end{abstract}

\begin{abstract}
An energy compensator of the Poschenrieder type for an atom probe field ion microscope is described. The compensator has a large acceptance angle, 0.1 radians. The mass resolution has been measured for different ion entrance angles and energy deficits, and is compared to the mass resolution calculated from the focusing errors of the compensator.
\end{abstract}

\section{I-INTRODUCTION}

In the atom probe field ion microscope, the mass of individual field evaporated ions is determined by time-of-flight spectrometry. The mass-to-charge ratio of an ion, $m / n$, is computed from the measured flight time, $t$, and the known acceleration voltage, $U$, according to the formula:

$$
m / n=2 e U t^{2} / l^{2}
$$

where $e$ is the elementary charge and $l$ the fight distance. In the original and still most used version of the instrument, ions are field evaporated by applying voltage pulses to the specimen [1]. Hovever, it was soon found that the mass resolution of the instrument was much poorer than could be expected from the uncertainties in measurement of $U$ and $t[2,3]$. In particular many ions appeared in mass spectra at a too high mass-to-charge value. The resulting tails towards the high mass end of the mass peaks were attributed to energy deficits: many ions were not field evaporated at the pulse peak, and many ions were also accelerated by a falling field $[4,5]$.

The work of Poschenrieder on time focusing mass spectrometers [6] made it possible to compensate for the energy deficits while retaining geometrical focusing onto the ion detector. The first atom probe with an electrostatic energy compensator of the Poschenrieder type was built by Müller and co-workers, and they obtained a very much improved mass resolution [2]. Since then several energy compensators of the same type have successfully been added to voltage pulsed atom probe instruments.

In Poschenrieder's original publication a numerical example of a compensator design is given. The acceptance angle is 0.04 radians in this example, and it appears that many compensators that have been added to atom probe instruments during the last ten years have had this geometry. Although giving a good mass resolution, this design has a somewhat limited acceptance angle which is a drawback for certain types of analyses, e. g. thin layers.

This paper describes the design and performance of a Poschenrieder energy compensator with a larger acceptance angle, 0.1 radians. The mass resolution has been measured as a function of entrance angle and energy deficit, and the results are compared with calculated time focusing errors.

\section{II - COMPENSATOR DESIGN}

The compensator consists of a linear drift path of length $g$, an electrostatic sector field produced by two toroidal electrodes of deflection angle $\Phi$, radial radius $r$ and axial radius $R$ of the central equipotential surface, and a second 
linear path, also of length $g$ (Fig. 1). In order to achieve time focusing and stigmatic imaging, the following relations must be fulfilled:

$$
g=2.33 r ; \quad c=r / R=0.249 ; \quad \Phi=163.1^{\circ}
$$

[7] - note the numerical error in [6]. For the present design a radius $r$ of $210 \mathrm{~mm}$ was selected, which gives a total flight path $l$ of $2 g+\Phi r \pi / 180$ or about $1570 \mathrm{~mm}$. The electrode separation is $70 \mathrm{~mm}$ and the entrance aperture is $\emptyset 50$ $\mathrm{mm}$, which corresponds to a (full) acceptance angle of sligtly more than 0.1 radians. The exit aperture is $70 \mathrm{~mm}$ wide.

The electrodes have a height of $120 \mathrm{~mm}$ and a thickness of about $10 \mathrm{~mm}$, and they were manufactured in the following way: A band was cut out from a $12 \mathrm{~mm}$ thick stainless steel plate, bent and welded to a ring. After annealing at $900^{\circ} \mathrm{C}$ the ring was rough-turned, annealed again at $500^{\circ} \mathrm{C}$, and turned to exact measure. The change in shape when cut open was small, accurately measured and accounted for upon mounting. The two electrodes are supported by precision machined glass-ceramic cylinders, which define the position of the electrode surfaces relative to a supporting steel plate with an accuracy of about $0.1 \mathrm{~mm}$.

A simple numerical calculation solving Laplace's equation for the potential between the electrodes (assuming for simplicity $R=\infty$ ) showed that fringe effects above and below the flight path have to be corrected for (Figure 2). Six compensating wires of $\varnothing 2 \mathrm{~mm}$ stainless steel were therefore mounted, $1 \mathrm{~cm}$ apart, between the electrodes at their upper and lower edges. The wires are held by glass-ceramic supports, and care was taken to shield as much of the glass-ceramic as possible in order to prevent charging up effects. With this arrangement the potential deviates less than $1 \%$ from the intended value within a volume of $\emptyset 50 \mathrm{~mm}$ around the central path (Fig. 2).

The potential in the toroidal field between the electrodes can be approximated by the following equation [8]:

$$
\varphi(u, v)=2 U_{o}\left[u-(1+c) u^{2} / 2+c v^{2} / 2\right]
$$

where $c$ is defined in $\mathrm{Eq} .2, u=(\rho-r) / r$ is the normalised radial coordinate and $v=z / r$ is the normalised axial coordinate, measured from the plane of the central path. $U_{o}$ is the accelerating voltage, which means that ions which do not suffer any energy deficits will have an energy of $n e U_{o}$. With this equation the required voltages on the electrodes and compensating wires can be calculated. The large separation between the electrodes means that rather high voltages have to be used, $-0.37 U_{o}$ and $+0.30 U_{o}$ on the inner and outer electrodes, respectively, with correspondingly higher requirements on high voltage supplies, feedthroughs and insulation.

The energy compensator was mounted onto an atom probe instrument which has been described elsewhere [9]. A laser beam was used as an aid during mechanical alignment of the ion optical axis of the compensator along the geometrical axis of the instrument (defined by the movement of the probe hole as the tip-to-channel-plate distance is changed).

TABLE I - Measured width of two $\mathrm{Ni}^{2+}$ mass peaks in atom probe spectra. Five different combinations of

\begin{tabular}{|c|c|c|c|c|c|c|c|c|}
\hline Column & 1 & 2 & 3 & 4 & 5 & 6 & 7 & 8 \\
\hline $\begin{array}{l}\text { Experi- } \\
\text { ment } \\
\text { number }\end{array}$ & $\begin{array}{l}\text { Tip-to- } \\
\text { screen } \\
\text { (cm) }\end{array}$ & $\begin{array}{l}\text { Pulse } \\
\text { fraction } \\
(\%)\end{array}$ & $\begin{array}{l}\text { Peak v } \\
\text { Ni-58 } \\
\text { (u) }\end{array}$ & $\begin{array}{l}t \text { base } \\
\text { Ni-60 } \\
\text { (u) }\end{array}$ & $\begin{array}{l}\text { Width } \\
\text { Ni-58 } \\
\text { (u) }\end{array}$ & $\begin{array}{l}\text { maximum } \\
\mathrm{Ni}-60 \\
\text { (u) }\end{array}$ & $\begin{array}{l}\text { “65\% } \\
\mathrm{Ni}-58 \\
\text { (u) }\end{array}$ & $\begin{array}{l}\text { " width } \\
\mathrm{Ni}-60 \\
\text { (u) }\end{array}$ \\
\hline $\begin{array}{l}1 \\
2 \\
3 \\
4 \\
5\end{array}$ & $\begin{array}{c}11.5 \\
8 \\
4 \\
2 \\
8\end{array}$ & $\begin{array}{l}15 \\
15 \\
15 \\
15 \\
29\end{array}$ & $\begin{array}{l}.17 \\
.15 \\
.19 \\
.24 \\
.26\end{array}$ & $\begin{array}{l}.15 \\
.17 \\
.18 \\
.25 \\
.26\end{array}$ & $\begin{array}{l}.03 \\
.06 \\
.01 \\
.01 \\
.01\end{array}$ & $\begin{array}{l}.03 \\
.06 \\
.08 \\
.08 \\
.01\end{array}$ & $\begin{array}{l}.03 \\
.04 \\
.07 \\
.07 \\
.04\end{array}$ & $\begin{array}{l}.03 \\
.04 \\
.07 \\
.07 \\
.06\end{array}$ \\
\hline
\end{tabular}
tip-to-screen distance and pulse amplitude were used. 


\section{III - RESULTS}

Experiments were performed with a specimen of pure nickel. The specimen temperature was $90 \mathrm{~K}$, the pressure less than $30 \mathrm{nPa}$, the evaporation voltage about $8 \mathrm{kV}$, and the evaporation pulse amplitude $15 \%$ of the standing voltage. The entrance angle to the compensator was varied between 17 and $100 \mathrm{mrad}$ by varying the distance between the channel-plate image intensifier, with its $\emptyset 2 \mathrm{~mm}$ aperture, and the specimen from 11.5 to $2 \mathrm{~cm}$. In addition, with an entrance angle of $25 \mathrm{mrad}$ a pulse amplitude of $29 \%$ was used.

For each set of parameters about 1200 ions were recorded. Examples of mass spectra obtained are shown in Figure 3. The width of the two largest $\mathrm{Ni}^{2+}$ mass peaks, from $\mathrm{Ni}-58$ and $\mathrm{Ni}-60$, was determined from the spectra both at half maximum and at the base. The results are given in Table I. As can be seen from the Table the peak width at half maximum is not a good measure of the shape of mass peaks, since due to the limited resolution of the timer this width can vary considerably if most ions "hit" one timer channel or if most ions are distributed evenly over two channels. In addition therefore the width of that part of each peak, around the peak maximum, in which $65 \%$ of the ions $\propto c c u r r e d$ was determined and is given in Table I (" $65 \%$ of ions").

As a comparison a spectrum of pure nickel, obtained with a straight atom probe using similar conditions (15\% pulse fraction and $67 \mathrm{mrad}$ entrance angle), is shown in Figure 4.

\section{IV - CALCULATION}

\section{Measurement errors}

Differentiating Eq. 1 we obtain for the error in mass-to-charge ratio:

$$
\Delta(m / n) /(m / n)=2 \Delta t / t+\Delta U / U
$$

Neglecting for the moment the focusing errors of the compensator, the error $\Delta t$ in Eq. 4 is simply the uncertainty in time measurement of the spectrometer, $\Delta t_{m}$. In the present case the time is measured with a $200 \mathrm{MHz}$ timer. Therefore the timing error consists of the sum of the timer start error and the timer stop error. Both are stochastic variables with constant probability, the former over the interval $(-5,0) \mathrm{ns}$ and the latter over tr : interval $(0,5) \mathrm{ns}$. The standard deviation of such a variable is $\sqrt{ }(25 / 12)$ or $1.44 \mathrm{~ns}$, so that the sum has the standard deviation $\sqrt{ }(25 / 6)$ or $2.04 \mathrm{~ns}$.

In the present case the flight time, $t$, is about $6.8 \mu \mathrm{s}$. The maximum timer error, $\Delta t_{m}$, is of course \pm 5 ns or about $\pm 0.7 \%$, which gives a maximum measurement error $\Delta(\mathrm{m} / \mathrm{n})_{\mathrm{m}}$ of $\pm 0.043 \mathrm{u}$ (atomic mass units). In comparison with the timer error, the error $\Delta U / U$ due to the uncertainty in voltage determination is small and will be neglected in the following. The full maximum measurement error is therefore $\Delta(\mathrm{m} / \mathrm{n})_{m}$, and this is entered in Table II, where we shall collect calculated maximum errors. We will then compare these with measured widths at the base of the mass peaks.

The standard deviation, 2 ns or about $0.3 \%$, corresponds to a standard deviation for $m / n$ of $\sigma_{m}=0.017 \mathrm{u}$. It can be shown that for the sum of two stochastic variables of constant probability over an interval, $65 \%$ of the ions occur within \pm one standard deviation. We enter $\sigma_{m}$ in Table $I I$, where we shall collect calculated " $65 \%$ of ions" errors. These will then be compared with measured half maximum and " $65 \%$ of ions" peak widths.

TABLE II - Calculated maximum measurement errors and focusing errors for the experimental conditions in Table I

\begin{tabular}{|c|c|c|c|c|c|c|c|c|}
\hline $\begin{array}{l}\text { Experi- } \\
\text { ment }\end{array}$ & $\begin{array}{l}2 \alpha=2 \beta \\
\text { (mrad) }\end{array}$ & $\begin{array}{l}\delta \\
(\% o)\end{array}$ & $\begin{array}{l}\Delta(m / n)_{m} \\
\text { (u) }\end{array}$ & $\begin{array}{l}\Delta(m / n) \alpha \\
(\mathrm{u})\end{array}$ & $\underset{\text { (u) }}{\Delta(m / n)} \beta$ & $\begin{array}{l}\Delta(m / n) \delta \\
(\mathrm{u})\end{array}$ & $\begin{array}{l}\Delta(m / n) \alpha \delta \\
(\mathrm{u})\end{array}$ & $\begin{array}{l}\Delta(m / n)_{t o t} \\
\text { (u) }\end{array}$ \\
\hline 1 & 17 & 41 & \pm .043 & -.001 & +.002 & +.043 & \pm .001 & $-.05+.09=.14$ \\
\hline 2 & 25 & 41 & \pm .043 & -.002 & +.005 & +.043 & \pm .001 & $-.05+.09=.14$ \\
\hline 3 & 50 & 41 & \pm .043 & -.007 & +.019 & +.043 & \pm .002 & $-.05+.11=.16$ \\
\hline 4 & 100 & 41 & \pm .043 & -.030 & +.076 & +.043 & \pm .004 & $-.08+.17=.25$ \\
\hline 5 & 25 & 79 & \pm .043 & -.002 & +.005 & +.157 & \pm .002 & $-.05+.21=.26$ \\
\hline
\end{tabular}




\section{Focusing errors}

\section{Maximum errors}

The second order approximation for the electric field in the toroidal compensator is given by Eq. 3 above. Using this approximation it is possible to compute the flight time of an ion of energy $U_{o}(1+\delta)$, (where $\delta=\Delta U / U_{o}$ is the energy deficit), radial entrance angle $\alpha$ and axial entrance angle $\beta$, to second order in $\alpha, \beta, \delta$ and ion source width $u_{o}$ and $v_{o}$ [10]. (The compensator is free from time focusing errors to first order in these quantities.) Neglecting terms in $u_{o}$ and $v_{o}$, which are very small for a field ion specimen, we have (Eq. 11 in [10]):

$$
\Delta t=\left(1 / v_{g}\right)\left[\alpha^{2} F \pm \alpha \delta G+\delta^{2} H+\beta^{2} L\right]
$$

where $v_{g}$ is the velocity of an ion of energy $U_{o}$, and $F, G, H$ and $L$ are constants. With the numerical values given in [10] we obtain, independent of flight distance and electrode separation:

$$
\Delta(m / n)=(m / n)\left[-0.407 \alpha^{2} \pm 0.069 \alpha \delta+1.05 \beta^{2}+0.865 \delta^{2}\right]
$$

It is straightforward to calculate $\Delta(m / n) \alpha$ and $\Delta(m / n){ }_{\beta}$ from the above formula and the known entrance angles $\alpha$ and $\beta$. The results are given in Table II. In order to calculate $\Delta(\mathrm{m} / n)_{\delta}$ and $\Delta(\mathrm{m} / n) \alpha \delta, \delta$ must be estimated. From the spectrum in Fig.4, obtained without any energy compensator, it can be deduced (by extrapolation of the approximately exponential peak tail) that the mass peak Ni-58 would have a width at the base of about 1.2 u for our particular experiment conditions and $15 \%$ pulse fraction, if no energy compensation were made. This gives a value for $\delta$ of $41 \%$ at $15 \%$ pulse and-assuming that $\delta$ increases linearly with pulse fraction-of $79 \%$ at $29 \%$ pulse. The expected $\Delta(\mathrm{m} / n) \delta$ and $\Delta(m / n) \alpha \delta$ when using a compensator can then be calculated from Eq. 6 , and they are given in Table II together with $\Delta(m / n)_{\text {max }}$, the sum of all maximum errors computed.

$$
\text { "65\% of ions" width }
$$

For the case of measurement errors it was possible to compute the " $65 \%$ of ions" width of the mass peaks. This quantity was also measured. Let us therefore also estimate the "65\% of ions" width caused by the focusing errors because of the spread in entrance angle of the ions and their energy deficits.

Since ions having a large radial entrance angle $\alpha$ have a shorter than normal flight time, and ions with a large axial entrance angle $\beta$ have a longer than normal flight time, ions originating from two diagonals of the probed circular area suffer no flight time error (Figure 5). The loci of equal time error are hyperbolas, and by calculating the area between these the fraction of ions which have less than a certain $\Delta(m / n)$ can be computed. The $\Delta(m / n)$ corresponding to $65 \%$ of the probed area for some of the experimental conditions are given in Table III.

For $15 \%$ pulse fraction, the energy deficit which $65 \%$ of the ions do not exceed can easily be deduced from the spectrum in Fig. 4, and the corresponding $\Delta(\mathrm{m} / \mathrm{n})$ computed from Eq. 6 is given in Table III together with an estimated value for $29 \%$ pulse, again assuming a linear increase in energy deficit.

TABLE III - Calculated width of mass peak within which $65 \%$ of the ions occur. The calculation was made for three of the experiments in Table I. The dominating contribution to the peak width is underlined.

\begin{tabular}{llllll}
\hline $\begin{array}{l}\text { Experi- } \\
\text { ment }\end{array}$ & $\begin{array}{l}2 \alpha=2 \beta \\
(\mathrm{mrad})\end{array}$ & $\delta$ & \multicolumn{3}{c}{ Calculated "65\% of ions"width (u) due to: } \\
& & $(\%)$ & measurement $\left(2 \sigma_{m}\right)$ & $\alpha$ and $\beta$ & $\delta$ \\
2 & 12.5 & 41 & $\frac{.04}{.04}$ & .002 & .001 \\
4 & 100 & 41 & .04 & .06 & .001 \\
5 & 12.5 & 79 & & .002 & .003 \\
\hline
\end{tabular}




\section{V-COMPARISON WTTH MEASUREMENTS}

Full peak width

The calculated total maximum errors, i.e. the sum (with proper signs) of maximum measurement errors and focusing errors, are given in the last column of Table II. These should be compared with the measured witdhs at the base (full peak width) of mass peaks Ni-58 and Ni-60, columns 3 and 4 in Table I. The agreement is good. It can be noted that the timer resolution and the energy deficits limit the mass resolution, measured at the peak base, to about $1 / 180$ at small entrance angles and energy deficits, whereas a large entrance angle or energy deficit gives a mass resolution of about $1 / 115$.

\section{“65\% of ions" peak width}

The mass resolution measured as peak width at half maximum is of course much higher. However, the simple width at half maximum is not a good measurement of the peak shape, as is evident from columns 5 and 6 in Table $I$. As an example, deducing a mass resolution of $.01 / 29=1 / 2900$ from the Ni-58 peak at large entrance angle or energy deficit would be meaningless. But the " $65 \%$ of ions" width seems to be a reproducable measure, which then should be compared with the calculated errors in Table III. It is not a straightforward procedure to add these errors, but the dominating error in each of the three cases in Table III (underlined) seems to agree quite well with the measured " $65 \%$ of ions" width in the last two colums of Table I. The "65\% of ions" widths correspond to a mass resolution of between about $1 / 410$ and $1 / 960$, and are apparently mainly caused by timing errors, except at large entrance angles.

\section{VI - SUMMARY}

1. An energy compensator with a large acceptance angle, 0.1 radians, was constructed. From a design point of view the major difference relative to a smaller acceptance angle compensator is that higher voltages have to be handled.

2. The full peak width (peak width at its base) was measured for different entrance angles and energy deficits, and compared with calculated maximum measurement errors and focusing errors. The agreement was good. For Ni at $8 \mathrm{kV}$, using a timer with $5 \mathrm{~ns}$ resolution and a flight path of $1.6 \mathrm{~m}$, the full peak width corresponds to a mass resolution of between $1 / 115$ and $1 / 180$ for the different cases.

3. To estimate the peak width at about half maximum, the mass range within which $65 \%$ of the ions occurred was found to be a suitable quantity. Again the agreement between measured " $65 \%$ of ions" widths and caiculated errors was good. The mass resolution measured in this way varied between $1 / 410$ and $1 / 960$.

\section{ACKNOWLEDGEMENTS}

It is a pleasure to acknowledge the workmanship of Mr. R. Söderlund and Mr. G. Reivall. I am grateful to Dr. H. Nordén for many helpful discussions, and to Mr. C. Jin and Ms. M. Wackfeldt for assisting with the drawing work. Mr. U. Rolander is thanked for help during the installation of the compensator. This work was supported by the National Swedish Board for Technical Development (STU).

\section{REFERENCES}

[1] Müller, E.W., Panitz, J.A. and McLane, S.B., Rev. Sci. Instrum. 39 (1968) 83.

[2] Müller, E.W. and Krishnaswamy, S.V., Rev. Sci. Instrum. 45 (1974) 1053.

[3] Waugh, A.R., D.Phil. thesis, Univ. of Cambridge (1975).

[4] Krishnaswamy, S.V. and Müller, E.W., Rev. Sci. Instrum. 45 (1974) 1049.

[5] Regan, B.J., Turner, P.J. and Southon, M.J., J. Phys. E: Sci. Instrum. 9 (1976) 187.

[6] Poschenrieder, W.P., Int. J. Mass Spectrom. Ion Phys. 9 (1972) 357.

[7] Sakai, A. and Sakurai, T., Jap. J. Appl. Phys. 23 (1984) 93.

[8] Wollnik, H., in "Focusing of Charged Particles", Ed. A. Septier, Academic Press, New York and London (1967) Vol II, p.163.

[9] Andrén, H-O. and Nordén, H., Scand. J. Metall. 8 (1979) 147.

[10] Oetjen, G-H. and Poschenrieder, W.P., Report IPP 9/15, Max-Planck-Institut für Plasmaphysik, Garching bei München (1974). 


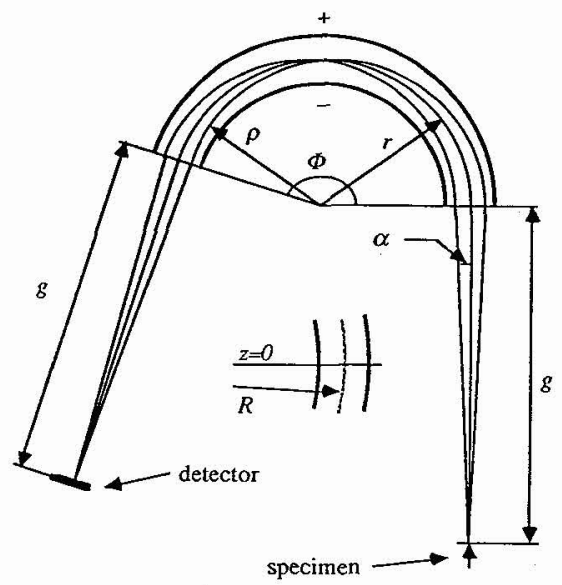

Fig. 1 - Geometry of the energy compensator.

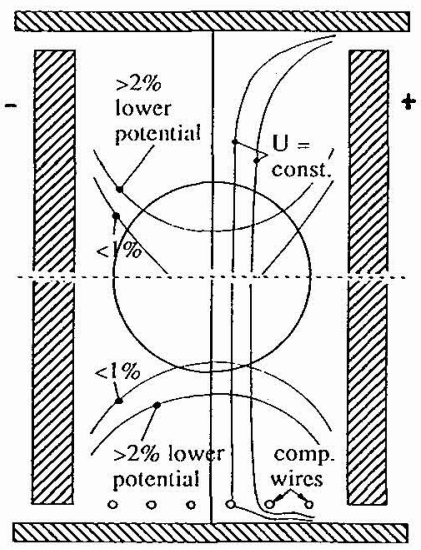

Fig. 2 - Calculated deviations in potential without (above) and with (below) compensating wires.
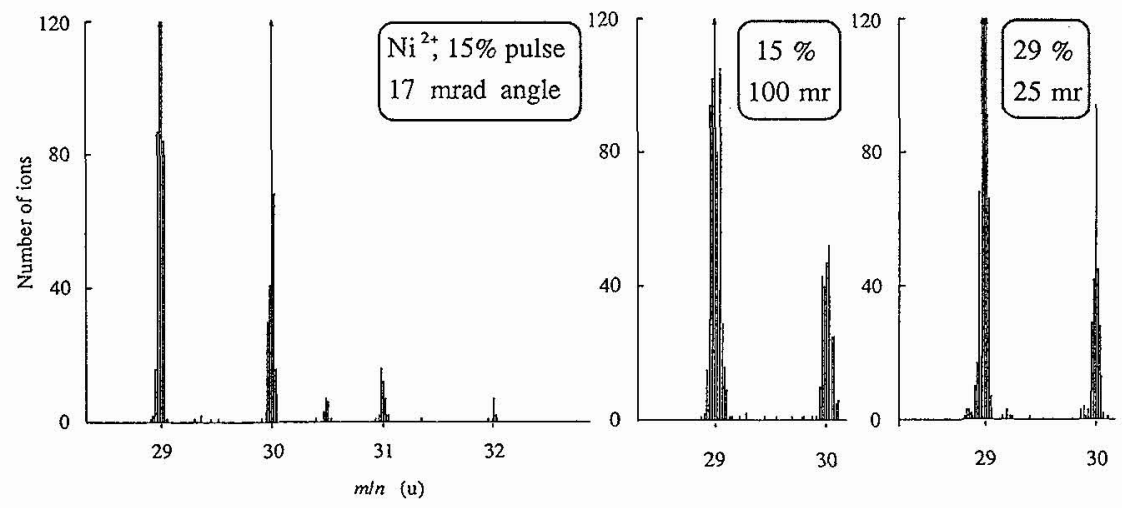

Fig. 3 - Atom probe mass spectra of Ni, obtained with different pulse fractions and entrance angles.

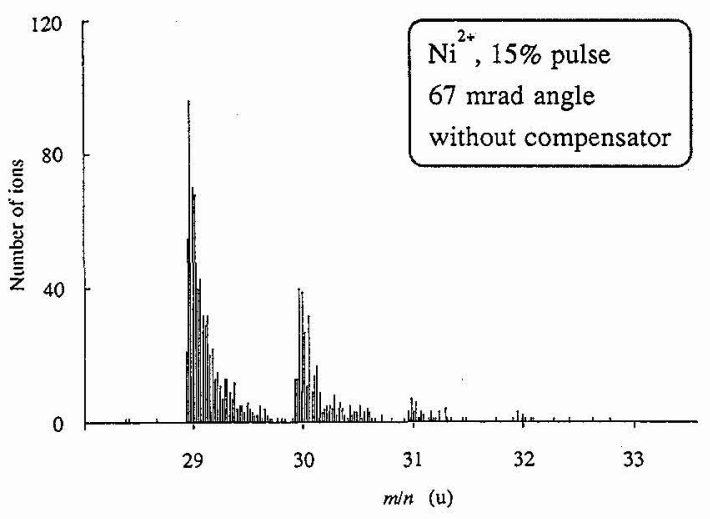

Fig. 4 - Mass spectrum of Ni obtained without an energy compensator (courtesy L. Karlsson).

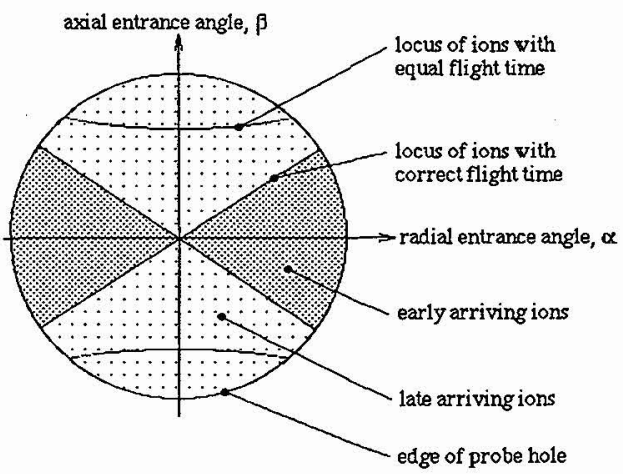

Fig. 5 - Schematic diagram of analysed area. Regions of time focusing errors due to entrance angle marked. 